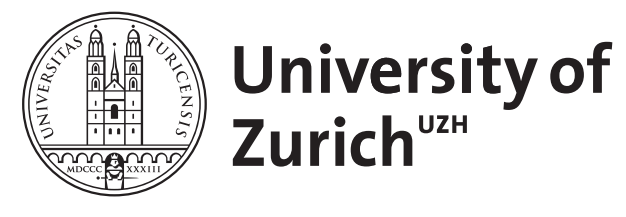

\title{
Metabolic control of adult neural stem cell behavior
}

Knobloch, Marlen ; Jessberger, Sebastian

\begin{abstract}
Neural stem cells generate new neurons throughout life in distinct regions of the mammalian brain. This process, called adult neurogenesis, is important for tissue homeostasis and physiological brain function. In addition, failing or altered neurogenesis has been associated with a number of diseases such as major depression and epilepsy. Thus, understanding the molecular mechanisms governing the neurogenic process in the adult brain may enable future therapeutic approaches to target neural stem/progenitor cells (NSPCs) and their progeny to ameliorate disease symptoms and/or disease progression. Recently, the control of cellular metabolism has emerged as a regulator of NSPC activity in the adult brain. Here we review recent findings that attempt to describe stage-specific modulations of metabolism to ensure proper neurogenesis and suggest future avenues of research aiming to understand how metabolism affects NSPC behavior.
\end{abstract}

DOI: https://doi.org/10.1007/s11515-015-1349-z

Posted at the Zurich Open Repository and Archive, University of Zurich

ZORA URL: https://doi.org/10.5167/uzh-120366

Journal Article

Published Version

Originally published at:

Knobloch, Marlen; Jessberger, Sebastian (2015). Metabolic control of adult neural stem cell behavior. Frontiers in Biology, 10(2):100-106.

DOI: https://doi.org/10.1007/s11515-015-1349-z 


\title{
MINI-REVIEW
}

\section{Metabolic control of adult neural stem cell behavior}

\author{
Marlen Knobloch ( $₫)$, Sebastian Jessberger ( $₫)$ \\ Brain Research Institute, Faculty of Medicine and Science, University of Zurich, 8057 Zurich, Switzerland
}

(C) Higher Education Press and Springer-Verlag Berlin Heidelberg 2015

\begin{abstract}
Neural stem cells generate new neurons throughout life in distinct regions of the mammalian brain. This process, called adult neurogenesis, is important for tissue homeostasis and physiological brain function. In addition, failing or altered neurogenesis has been associated with a number of diseases such as major depression and epilepsy. Thus, understanding the molecular mechanisms governing the neurogenic process in the adult brain may enable future therapeutic approaches to target neural stem/progenitor cells (NSPCs) and their progeny to ameliorate disease symptoms and/or disease progression. Recently, the control of cellular metabolism has emerged as a regulator of NSPC activity in the adult brain. Here we review recent findings that attempt to describe stage-specific modulations of metabolism to ensure proper neurogenesis and suggest future avenues of research aiming to understand how metabolism affects NSPC behavior.
\end{abstract}

Keywords adult neurogenesis, metabolic switch, quiescence, proliferation, differentiation

\section{Introduction}

Contrary to the long-held belief that the neurogenic activity of NSPCs tapers off after embryonic and early postnatal development, it was first shown in the mid-1960s and accepted by the field in the late 1990s that NSPCs in distinct regions of the mammalian brain retain their neurogenic potential throughout life (Altman and Das, 1964; Kuhn et al., 1996; Eriksson et al., 1998). Thus, the adult mammalian brain retains the capacity to generate new neurons that over the course of several weeks mature and functionally integrate into the pre-existing circuitries (Braun and Jessberger, 2014; Christian et al., 2014). However, adult neurogenesis is not widespread but rather restricted to discrete areas. Whereas in the rodent brain a substantial number of NSPCs persist in the subventricular zone (SVZ), lining the lateral ventricles, that give rise to a diverse set of olfactory neurons (Doetsch et al., 1997; 1999), this site of neurogenesis appears to be absent in the human (Bergmann et al., 2012). However, accumulating evidence suggests that in both rodent and human brains a substantial number of neurons are generated in the second main neurogenic area: the dentate gyrus (DG), the part of the

Received November 21, 2014; accepted February 10, 2015 Correspondence: ${ }^{a}$ Marlen Knobloch; ${ }^{b}$ Sebastian Jessberger E-mail: ${ }^{a}$ knobloch@hifo.uzh.ch; ${ }^{b}$ jessberger@hifo.uzh.ch hippocampus that is critically involved in certain forms of learning and memory (Kuhn et al., 1996; Eriksson et al., 1998; Spalding et al., 2013). Strikingly, failing or altered hippocampal neurogenesis has been associated with several neuropsychiatric diseases, among others major depression, epilepsy, cognitive aging, and a number of neurodegenerative diseases (Zhao et al., 2008). Support for a role of newborn dentate granule cells for proper hippocampal function came from a number of studies showing hippocampus-dependent behavioral alterations upon experimental decrease or increase of neurogenesis levels in rodents (Deng et al., 2010). Given the potential role of life-long neurogenesis for cognition and hippocampus-dependent emotional control (Deng et al., 2010; Kheirbek et al., 2012), tremendous efforts have been undertaken to understand the cellular and molecular mechanisms governing the neurogenic process in the brain. Thus, over the past 15 years a number of intrinsic and nichedependent regulators of neurogenesis have been identified that regulate distinct steps during the neurogenic process (Lie et al., 2005; Ge et al., 2006; Zhao et al., 2008; Favaro et al., 2009; Ables et al., 2010; Kim et al., 2012; Song et al., 2012). Only very recently a critical role of cellular metabolism to regulate the activity of adult NSPCs has been identified (Knobloch et al., 2013), in line with the important role of metabolism in other somatic stem cell systems (Nakada et al., 2010; Gan et al., 2010; Gurumurthy et al., 2010; Folmes et al., 2012; Ito and Suda, 2014). Here we review recent findings 
describing a role for metabolic regulation during distinct NSPC states and describe potential routes of future research.

\section{Metabolic requirements of proliferating adult NSPCs}

A tight regulation of NSPC quiescence and proliferation is crucial to ensure life-long neurogenesis and prevent exhaustion or uncontrolled growth of the stem cell pool. Most studies aimed at understanding the regulation of NSPC proliferation and quiescence have focused on the role of transcription factors and molecular pathways such as Wnt signaling and IGF signaling that have been previously implicated in growth regulation (Orford and Scadden, 2008; Suh et al., 2009). Many of these transcription factors and pathways ultimately influence cell metabolism, however, only over the last few years has the metabolic state of stem cells per se garnered attention (Varum et al., 2011; Folmes et al., 2012; Zhang et al., 2012), particularly in the field of hematopoietic stem cell (HSC) research (Gan et al., 2010; Nakada et al., 2010; Gurumurthy et al., 2010; Suda et al., 2011). So far, very little is known about the metabolic state of NSPCs and how it might influence NSPC behavior. Recently, we showed that de novo lipogenesis is crucial for NSPC proliferation (Knobloch et al., 2013). Similar to cancer cells, which produce the majority of their lipids de novo rather than taking them up from the environment (Menendez and Lupu, 2007), NSPCs also upregulate the lipogenic pathway. In addition, we showed that proliferating NSPCs have high activity levels of the key enzyme fatty acid synthase (Fasn) and that proliferation is significantly reduced upon pharmacological or genetic inhibition of Fasn. When Fasn is blocked in adult NSPCs in vivo using an inducible Fasn knockout mouse line, neurogenesis is dramatically inhibited. We have furthermore found that Spot14, a protein whose expression is largely restricted to quiescent NSPCs, acts as a regulator of Fasn by reducing Malonyl-CoA, which serves as a substrate for Fasn. When Spot14 is knocked down in vivo, the relatively quiescent Spot14 positive NSPCs increase proliferation, indicating that Spot14 might act as a molecular brake to regulate the activity of a specific metabolic program, namely de novo lipogenesis (Knobloch et al., 2013). The reasons for the importance of de novo fatty acid synthesis in proliferating NSPCs are not yet entirely understood. As most of the newly generated fatty acids end up in membrane lipids, it is likely that the NSPCs need this pathway to build new membranes for rapid proliferation. However, palmitic acid, the major fatty acid produced by Fasn, is also used for palmitoylation, a protein modification that has been shown to be important for many proteins involved in stem cell regulation such as for instance Wnt and Hedgehog proteins as well as for synaptic plasticity (Iwanaga et al., 2009; Fukata and Fukata, 2010). Furthermore, as fatty acids provide a means to efficiently store energy, these lipids might also be used by NSPCs for energy production.

Interestingly, besides the lipogenic phenotype, proliferating NSPCs also share other metabolic pathways with cancer cells, and it has been proposed that such metabolic characteristics might be a universal feature of proliferating cells in general (Vander Heiden et al., 2009). An increase in (aerobic) glycolysis, whereby glucose is fermented into lactate despite the availability of oxygen, is common to many stem cells (reviewed by Folmes et al., 2012; Ito and Suda, 2014). This effect was first discovered in cancer cells by Otto Warburg and is known as the "Warburg effect." It is emerging that with such increased glycolytic flux and only partial breakdown of glucose, more metabolic intermediates are available for the biosynthesis of cellular building blocks, which are required for proliferation (Vander Heiden et al., 2009). The Warburg effect also seems to occur in proliferating NSPCs, as they have been shown to have high glycolytic flux and increased lactate production (reviewed by Kim et al., 2014). Furthermore, a recent study showed that NSPCs are more susceptible to glycolytic inhibition than primary neurons, even in the presence of alternative substrates for oxidative phosphorylation such as pyruvate (Candelario et al., 2013), implying that the glycolytic flux is not increased to fuel oxidative phosphorylation, but rather to provide metabolic intermediates. Taken together, many proliferating stem cells, including proliferating NSPCs, seem to share metabolic features that are similar in cancer cells.

\section{Metabolism of quiescent adult NSPCs}

It is now becoming apparent that stem cells are indeed in a metabolic state that is different from their progeny (Varum et al., 2011; Folmes et al., 2012; Knobloch et al., 2013) and that such metabolic differences influence cell behavior. A shared feature of many quiescent stem cells is their relative low levels of oxidative phosphorylation, probably due to the hypoxic environment in which they are residing. Low oxidative phosphorylation might also protect these quiescent stem cells from DNA damage caused by reactive oxygen species (ROS), which are produced during oxidative phosphorylation. The study of metabolic features of quiescent NSPCs is especially challenging, as they are activated and begin to proliferate when they are isolated from their in vivo niche and exposed to culture media containing growth factors (Costa et al., 2011), which likely alters their metabolism. In addition, the lack of good markers to prospectively isolate quiescent NSPCs and the relatively large numbers of cells required for metabolomics profiling has hindered the characterization of the metabolic state of quiescent NSPCs. Spot14, which is very selectively expressed in quiescent NSPCs and is functionally involved in regulating lipid metabolism, provides an interesting candidate (Knobloch et al., 2013) and metabolic profiling of Spot14 positive cells directly isolated from the brain might give further insight into 
the metabolic pathways active in quiescent NSPCs. As Spot14 positive NSPCs have lower levels of Malonyl-CoA (Knobloch et al., 2013), and as Malonyl-CoA is a negative regulator of fatty acid oxidation, it is possible that these quiescent Spot14 positive NSPCs utilize fatty acid oxidation. This is an intriguing concept, as a recent publication in the field of hematopoiesis showed that the most primitive HSC population uses fatty acid oxidation to maintain self-renewal (Ito et al., 2012). We are currently investigating the role of fatty acid oxidation in NSPCs and have observed that this pathway is indeed required, especially for the most quiescent NSPC population (Knobloch et al., unpublished). The detailed mechanisms remain to be elucidated.

\section{Metabolic influence on NSPC behavior}

Given the differences in metabolism between quiescent and proliferating stem cells, the question is whether these metabolic differences are a consequence of altered cell behavior or a prerequisite for it. To answer this, specific manipulation of distinct metabolic pathways are required, however this is extremely challenging as there is a complex interplay between different metabolic pathways due to shared metabolites, and the downregulation of a specific pathway often affects other metabolic pathways. Thus, great care has to be taken in interpreting results. Metabolic flux analyses, used to determine the actual rate of metabolite turnover, might provide a tool to address this complex interplay (reviewed by Sims et al., 2013). By using specific pathway inhibitors in combination with metabolic flux analyses, it should be possible to dissect the role of different metabolic pathways on stem cell behavior in vitro. Addressing their effects on proliferation and fate decision will provide important insights into basic stem cell biology. Strong evidence that the metabolic state is indeed a prerequisite and not a mere consequence of stem cell behavior comes from the induced pluripotent stem cell (iPSC) field. During reprogramming of fibroblasts into iPSCs, the somatic cells displayed a switch in their metabolic profile from an oxidative to a glycolytic phenotype prior to expression of pluripotent genes (Folmes et al., 2011). Blockade of glycolytic enzyme activity blunted reprogramming efficiency, indicating that a certain metabolic state is required to facilitate reprogramming. How exactly metabolism influences reprogramming remains to be elucidated, but it has been suggested that histone modifying enzymes can directly link metabolism and gene transcription/ epigenetic modifications through their need of metabolic coenzymes (Teperino et al., 2010).

Whether a metabolic switch occurs in NSPCs prior to fate changes, i.e. from quiescence to proliferation or from proliferation to differentiation, remains to be addressed. Studying neural stem cells in Drosophila (called neuroblasts), Homem and colleagues (2014) have recently published the first evidence that a metabolic switch indeed precedes cell- cycle exit and subsequent differentiation. Drosophila neuroblasts divide hundreds of times in a self-renewing mode before they shrink in size and undergo a symmetric terminal differentiation during metamorphosis. None of the common growth control pathways seem to be responsible for this phenomenon. Instead, the authors found a metabolic switch in neuroblasts from glycolysis to oxidative phosphorylation induced by the steroid hormone ecdysone and the Mediator complex, which lead to shrinkage and subsequent terminal differentiation. Importantly, blocking this switch by inhibiting the oxidative phosphorylation machinery prevented cell shrinkage and extended the life span of the pupal neuroblasts (Homem et al., 2014). Although the detailed mechanisms are not yet clear, increased catabolism through oxidative phosphorylation might prevent the accumulation of intermediates needed for the biosynthetic pathway, thus leading to reduced growth and cell-cycle exit. Whether this holds true for mammalian NSPCs remains to be determined. Further evidence that there is an increase in oxidative phosphorylation with neuronal differentiation comes from a recent study by Steib and colleagues, who have shown that the development of new neurons in adult mice is paralleled by extensive changes in mitochondrial mass, distribution, and shape (Steib et al., 2014). When inhibiting a mitochondrial fission factor necessary for increasing the numbers of mitochondria, maturation and survival of newborn neurons was strongly decreased. Although the authors did not directly address the metabolic properties of the newborn neurons, it is highly likely that the observed increase in mitochondrial mass is accompanied by an increase in oxidative metabolism.

\section{Environmental impact on adult neural stem cell metabolism}

Extrinsic stimuli having a positive or negative impact on adult NSPC behavior have been widely documented. Voluntary wheel running and enriched environment, for instance, lead to increased proliferation and survival of NSPCs and newborn neurons (Ma et al., 2009). On the contrary, aging negatively affects proliferation and neurogenesis (Knoth et al., 2010; Christian et al., 2014). Whether these extrinsic regulators directly alter the metabolic state of NSPCs is not clear. In a study addressing the effects of neurogenic modulators on Spot14 positive NSPCs in vivo, we showed that cells expressing this metabolically functional marker indeed react to extrinsic stimuli: running resulted in an increase in proliferating Spot14 positive NSPCs whereas aging reduced the number of Spot14 positive NSCPs (Knobloch et al., 2014).

Interestingly, a recent report by Chorna and colleagues (2013) showed that upon running, Fasn mRNA was significantly and specifically upregulated in the hippocampus of adult mice. The upregulation of Fasn mRNA was accompanied by higher palmitic acid levels and an increase 
in proliferating NSPCs. Furthermore, when Fasn was chronically inhibited by intracerebroventricular micro infusion of a Fasn inhibitor, the increase in proliferation was prevented and the exercise-mediated cognitive enhancement was disrupted. These data provide evidence that the metabolic program of NSPCs can be directly influenced by extrinsic stimuli and confirm the important role of Fasn for NSPCs (Knobloch et al., 2013).

The age-related decline in neurogenesis has been robustly documented (Kuhn et al., 1996; Knoth et al., 2010; Ben Abdallah et al., 2010; Villeda et al., 2011), although it is currently under debate if this is due to an exhausted pool of NSPCs or whether the stem cells remain but stop proliferating (Lugert et al., 2010; Encinas et al., 2011; Bonaguidi et al., 2012).The decline in neurogenesis with aging has been associated with blood-borne factors present in the systemic milieu, such as various chemokines which are increased upon aging and might exert negative effects on NSPCs (Villeda et al., 2011), but the detailed mechanisms remain to be addressed. A proteomic comparison between NSPCs derived from young and aged mice revealed an altered metabolic phenotype upon aging including decreased mitochondrial quantity and lowered oxygen consumption rates and a shift toward more glycolytic metabolism (Stoll et al., 2011). As quiescent stem cells in general seem to have rather reduced oxidative phosphorylation along with having more primitive mitochondria and using the glycolytic pathway (see above), these data suggest an increased quiescence of NSPCs upon aging. However, whether such a metabolic shift is functionally responsible for the reduced neurogenesis needs to be tested experimentally. Metabolic changes have also been suggested as the underlying cause for the age-related decline in a recent study by Stein and Imai (Stein and Imai, 2014). The essential cofactor nicotinamide adenine dinucleotide $\left(\mathrm{NAD}^{+}\right)$was markedly reduced in aged NSPCs due to a decline of the rate-limiting enzyme in the biosynthetic pathway of $\mathrm{NAD}^{+}$, nicotinamide phosphoribosyl transferase (Nampt). Inhibition of Nampt in vitro and in vivo reduced proliferation of NSPCs and systemic administration of the Nampt product nicotinamide mononucleotide in aged mice prevented the radial glia like stem cell pool from diminishing. These data suggest that direct targeting of metabolic pathways might provide a novel avenue to treat the age-related decline in neurogenesis, for instance by providing essential metabolic intermediates via nutrition.

A few groups have studied the overall influence of nutrition on neurogenesis and NSPCs, specifically the role of a high fat diet and caloric restriction. Although there are some controversial results, it seems that a high fat diet leads to a decrease in proliferation of NSPCs (Lindqvist et al., 2006; Park et al., 2010; Boitard et al., 2012), whereas caloric restriction has beneficial effects on neurogenesis, probably due to increased survival of newborn neurons (Lee et al., 2000; 2002). However the mechanisms are poorly understood and whether NSPCs and their progeny are directly altering their metabolic program upon major changes incirculating nutrients is not known.

The availability of peripheral nutrients, not only glucose levels but also the amounts of circulating lipids, is sensed in hypothalamic centers that regulate feeding and fasting behavior (Morton et al., 2006). Remarkably, this brain area has also been shown to have ongoing neurogenesis, mediated by so-called tanycytes that also show radial glia like phenotypes, and the formation of new neurons in the hypothalamus has been associated with energy balance (Kokoeva et al., 2005; Lee and Blackshaw, 2012; Li et al., 2012). Furthermore, a recent publication demonstrated that these stem cells, in contrast to NSPCs in the DG, increased their proliferation upon high-fat diet (Lee et al., 2012). These data suggest that there are indeed direct influences of circulating nutrients on NSPC behavior, a finding that might be of clinical relevance given the high fat diet of the Western World. The detailed mechanisms however remain to be elucidated.

\section{Conclusions}

Over the last few years metabolic control has been identified as an important regulator of somatic stem cell activity in a variety of tissue-specific stem cells, including adult NSPCs. However, we are just beginning to understand how switches between proliferating and quiescent NSPC states are orchestrated. Could it be that a plethora of signaling pathways converge on control of distinct metabolic states? This hypothesis is supported by the findings that a number of key regulators of neurogenesis such as BMPs, Shh, and FoxOs have been implicated in controlling metabolic states outside of the brain (Favaro et al., 2009; Paik et al., 2009; Renault et al., 2009; Schulz and Tseng, 2009; Mira et al., 2010; Teperino et al., 2012; Eijkelenboom and Burgering, 2013; Schulz et al., 2013). Moreover, future studies will test if metabolic changes simply occur secondary to fate switches or if altering metabolic states may be instructive for NSPC behavior. In addition, it will be of interest to test how similar or dissimilar distinct somatic stem cell types are with regards to their metabolic state. Can we identify a metabolic code of somatic stem cell multipotency, quiescence or activation?

On a more translational level it will be of interest to analyze how identified human mutations in genes encoding for metabolic regulators may contribute to human disease phenotypes due to NSPC-associated alterations. For example, recent work identified a point mutation in the human Fasn gene that is associated with non-syndromic cognitive impairment, even though it remains unclear at this time if this can be attributed to altered stem cell-associated plasticity (Najmabadi et al., 2011).

Although we do not fully understand the mechanisms of metabolic control of NSPC behavior yet, there is strong evidence that the metabolic state is a novel key player 


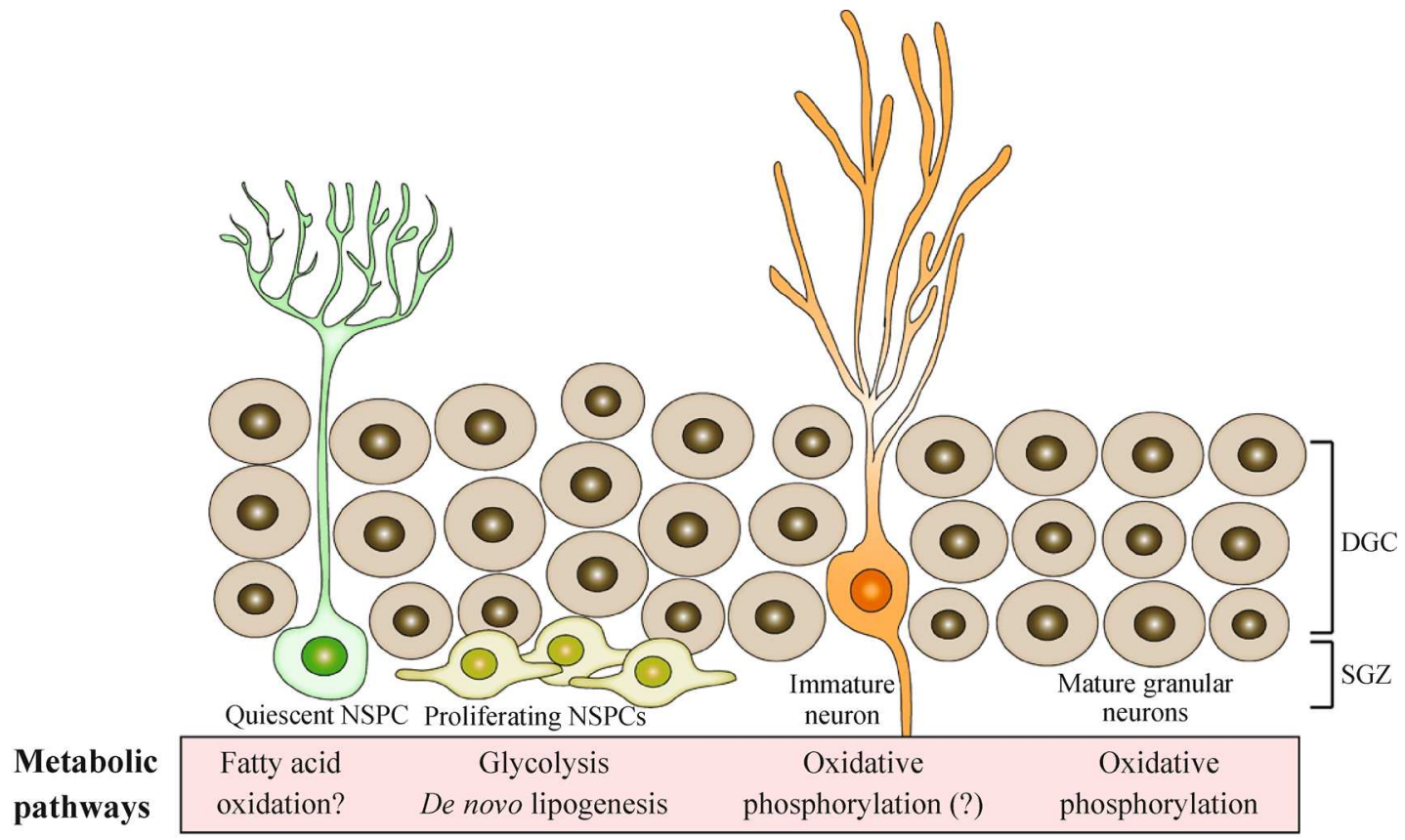

Figure 1 Schematic representation of metabolic pathways active in adult NSPCs and their progeny. Question marks indicate putative active pathways that need to be confirmed. SGZ, subgranular zone; DGC, dentate granule cell layer.

regulating the balance between stem cell quiescence/activation and subsequent differentiation (Fig. 1).

\section{Compliance with ethics guidelines}

Marlen Rnobloch and Sebastian Jessoerger declare that they have no conflict of interest.

\section{References}

Ables J L, Decarolis N A, Johnson M A, Rivera P D, Gao Z, Cooper D C, Radtke F, Hsieh J, Eisch A J (2010). Notch1 is required for maintenance of the reservoir of adult hippocampal stem cells. J Neurosci, 30(31): 10484-10492

Altman J, Das G D (1964). Autoradiographic examination of the effects of enriched environment on the rate of glial multiplication in the adult rat brain. Nature, 204(4964): 1161-1163

Ben Abdallah N M B, Slomianka L, Vyssotski A L, Lipp H P (2010). Early age-related changes in adult hippocampal neurogenesis in C57 mice. Neurobiol Aging, 31(1): 151-161

Bergmann O, Liebl J, Bernard S, Alkass K, Yeung M S Y, Steier P, Kutschera W, Johnson L, Landén M, Druid H, Spalding K L, Frisén J (2012). The age of olfactory bulb neurons in humans. Neuron, 74(4): 634-639

Boitard C, Etchamendy N, Sauvant J, Aubert A, Tronel S, Marighetto A, Layé S, Ferreira G (2012). Juvenile, but not adult exposure to high-fat diet impairs relational memory and hippocampal neurogenesis in mice. Hippocampus, 22(11): 2095-2100
Bonaguidi M A, Song J, Ming G L, Song H (2012). A unifying hypothesis on mammalian neural stem cell properties in the adult hippocampus. Curr Opin Neurobiol, 22(5): 754-761

Braun S M G, Jessberger S (2014). Adult neurogenesis and its role in neuropsychiatric disease, brain repair and normal brain function. Neuropathol Appl Neurobiol, 40(1): 3-12

Candelario K M, Shuttleworth C W, Cunningham L A (2013). Neural stem/progenitor cells display a low requirement for oxidative metabolism independent of hypoxia inducible factor-1alpha expression. J Neurochem, 125(3): 420-429

Chorna N E, Santos-Soto I J, Carballeira N M, Morales J L, de la Nuez J, Cátala-Valentin A, Chornyy A P, Vázquez-Montes A, De Ortiz S P (2013). Fatty acid synthase as a factor required for exercise-induced cognitive enhancement and dentate gyrus cellular proliferation. PLoS ONE, 8(11): e77845

Christian K M, Song H, Ming G L (2014). Functions and dysfunctions of adult hippocampal neurogenesis. Annu Rev Neurosci, 37(1): 243262

Costa M R, Ortega F, Brill M S, Beckervordersandforth R, Petrone C, Schroeder T, Götz M, Berninger B (2011). Continuous live imaging of adult neural stem cell division and lineage progression in vitro. Development, 138(6): 1057-1068

Deng W, Aimone J B, Gage F H (2010). New neurons and new memories: how does adult hippocampal neurogenesis affect learning and memory? Nat Rev Neurosci, 11(5): 339-350

Doetsch F, García-Verdugo J M, Alvarez-Buylla A (1997). Cellular composition and three-dimensional organization of the subventricular germinal zone in the adult mammalian brain. J Neurosci, 17(13): 5046-5061

Doetsch F, García-Verdugo J M, Alvarez-Buylla A (1999). Regeneration of a germinal layer in the adult mammalian brain. Proc Natl Acad Sci 
USA, 96(20): 11619-11624

Eijkelenboom A, Burgering B M T (2013). FOXOs: signalling integrators for homeostasis maintenance. Nat Rev Mol Cell Biol, 14(2): 83-97

Encinas J M, Michurina T V, Peunova N, Park J H, Tordo J, Peterson D A, Fishell G, Koulakov A, Enikolopov G (2011). Division-coupled astrocytic differentiation and age-related depletion of neural stem cells in the adult hippocampus. Cell Stem Cell, 8(5): 566-579

Eriksson P S, Perfilieva E, Björk-Eriksson T, Alborn A M, Nordborg C, Peterson D A, Gage F H (1998). Neurogenesis in the adult human hippocampus. Nat Med, 4(11): 1313-1317

Favaro R, Valotta M, Ferri A L M, Latorre E, Mariani J, Giachino C, Lancini C, Tosetti V, Ottolenghi S, Taylor V, Nicolis S K (2009). Hippocampal development and neural stem cell maintenance require Sox2-dependent regulation of Shh. Nat Neurosci, 12(10): 1248-1256

Folmes C D L, Dzeja P P, Nelson T J, Terzic A (2012). Metabolic plasticity in stem cell homeostasis and differentiation. Cell Stem Cell, 11(5): 596-606

Folmes C D L, Nelson T J, Martinez-Fernandez A, Arrell D K, Lindor J Z, Dzeja P P, Ikeda Y, Perez-Terzic C, Terzic A (2011). Somatic oxidative bioenergetics transitions into pluripotency-dependent glycolysis to facilitate nuclear reprogramming. Cell Metab, 14(2): 264-271

Fukata Y, Fukata M (2010). Protein palmitoylation in neuronal development and synaptic plasticity. Nat Rev Neurosci, 11(3): $161-75$

Gan B, Hu J, Jiang S, Liu Y, Sahin E, Zhuang L, Fletcher-Sananikone E, Colla S, Wang Y A, Chin L, Depinho R A (2010). Lkb1 regulates quiescence and metabolic homeostasis of haematopoietic stem cells. Nature, 468(7324): 701-704

Ge S, Goh E L K, Sailor K A, Kitabatake Y, Ming G L, Song H (2006). GABA regulates synaptic integration of newly generated neurons in the adult brain. Nature, 439(7076): 589-593

Gurumurthy S, Xie S Z, Alagesan B, Kim J, Yusuf R Z, Saez B, Tzatsos A, Ozsolak F, Milos P, Ferrari F, Park P J, Shirihai O S, Scadden D T, Bardeesy N (2010). The Lkb1 metabolic sensor maintains haematopoietic stem cell survival. Nature, 468(7324): 659-663

Homem C C F, Steinmann V, Burkard T R, Jais A, Esterbauer H, Knoblich J A (2014). Ecdysone and mediator change energy metabolism to terminate proliferation in Drosophila neural stem cells. Cell, 158(4): 874-888

Ito K, Carracedo A, Weiss D, Arai F, Ala U, Avigan D E, Schafer Z T, Evans R M, Suda T, Lee C H, Pandolfi P P (2012). A PML-PPAR- $\delta$ pathway for fatty acid oxidation regulates hematopoietic stem cell maintenance. Nat Med, 18(9): 1350-1358

Ito K, Suda T (2014). Metabolic requirements for the maintenance of self-renewing stem cells. Nat Rev Mol Cell Biol, 15(4): 243-256

Iwanaga T, Tsutsumi R, Noritake J, Fukata Y, Fukata M (2009). Progress in lipid research. Prog Lipid Res, 48: 117-127

Kheirbek M A, Klemenhagen K C, Sahay A, Hen R (2012). Neurogenesis and generalization: a new approach to stratify and treat anxiety disorders. Nat Neurosci, 15(12): 1613-1620

Kim D Y, Rhee I, Paik J (2014). Metabolic circuits in neural stem cells. Cell Mol Life Sci, 71(21): 4221-4241

Kim J Y, Liu C Y, Zhang F, Duan X, Wen Z, Song J, Feighery E, Lu B, Rujescu D, St Clair D, Christian K, Callicott J H, Weinberger D R, Song H, Ming G L (2012). Interplay between DISC1 and GABA signaling regulates neurogenesis in mice and risk for schizophrenia. Cell, 148(5): 1051-1064

Knobloch M, Von Schoultz C, Zurkirchen L, Braun S M G, Vidmar M, Jessberger S (2014) Spot14-positive neural stem/progenitor cells in the hippocampus respond dynamically to neurogenic regulators. Stem Cell Rep, 3: 1-8

Knobloch M, Braun S M G, Zurkirchen L, von Schoultz C, Zamboni N, Araúzo-Bravo M J, Kovacs W J, Karalay O, Suter U, Machado R A, Roccio M, Lutolf M P, Semenkovich C F, Jessberger S (2013). Metabolic control of adult neural stem cell activity by Fasndependent lipogenesis. Nature, 493(7431): 226-230

Knoth R, Singec I, Ditter M, Pantazis G, Capetian P, Meyer R P, Horvat V, Volk B, Kempermann G (2010). Murine features of neurogenesis in the human hippocampus across the lifespan from 0 to 100 years. PLoS ONE, 5(1): e8809

Kokoeva M V, Yin H, Flier J S (2005). Neurogenesis in the hypothalamus of adult mice: potential role in energy balance. Science, 310(5748): 679-683

Kuhn H G, Dickinson-Anson H, Gage F H (1996). Neurogenesis in the dentate gyrus of the adult rat: age-related decrease of neuronal progenitor proliferation. J Neurosci, 16(6): 2027-2033

Lee D A, Bedont J L, Pak T, Wang H, Song J, Miranda-Angulo A, Takiar V, Charubhumi V, Balordi F, Takebayashi H, Aja S, Ford E, Fishell G, Blackshaw S (2012). Tanycytes of the hypothalamic median eminence form a diet-responsive neurogenic niche. Nat Neurosci, 15 (5): 700-702

Lee D A, Blackshaw S (2012). Functional implications of hypothalamic neurogenesis in the adult mammalian brain. Int J Dev Neurosci, 30 (8): 615-621

Lee J, Duan W, Long J M, Ingram D K, Mattson M P (2000). Dietary restriction increases the number of newly generated neural cells, and induces BDNF expression, in the dentate gyrus of rats. J Mol Neurosci, 15(2): 99-108

Lee J, Seroogy K B, Mattson M P (2002). Dietary restriction enhances neurotrophin expression and neurogenesis in the hippocampus of adult mice. J Neurochem, 80(3): 539-547

Li J, Tang Y, Cai D (2012). IKK $\beta / \mathrm{NF}-\kappa \mathrm{B}$ disrupts adult hypothalamic neural stem cells to mediate a neurodegenerative mechanism of dietary obesity and pre-diabetes. Nat Cell Biol, 14(10): 999-1012

Lie D C, Colamarino S A, Song H J, Désiré L, Mira H, Consiglio A, Lein E S, Jessberger S, Lansford H, Dearie A R, Gage F H (2005). Wnt signalling regulates adult hippocampal neurogenesis. Nature, 437 (7063): 1370-1375

Lindqvist A, Mohapel P, Bouter B, Frielingsdorf H, Pizzo D, Brundin P, Erlanson-Albertsson C (2006). High-fat diet impairs hippocampal neurogenesis in male rats. Eur J Neurol, 13(12): 1385-1388

Lugert S, Basak O, Knuckles P, Haussler U, Fabel K, Götz M, Haas C A, Kempermann G, Taylor V, Giachino C (2010). Quiescent and active hippocampal neural stem cells with distinct morphologies respond selectively to physiological and pathological stimuli and aging. Cell Stem Cell, 6(5): 445-456

Ma D K, Kim W R, Ming G L, Song H (2009). Activity-dependent extrinsic regulation of adult olfactory bulb and hippocampal neurogenesis. Ann N Y Acad Sci, 1170(1): 664-673

Menendez J A, Lupu R (2007). Fatty acid synthase and the lipogenic phenotype in cancer pathogenesis. Nat Rev Cancer, 7(10): 763-777 Mira H, Andreu Z, Suh H, Lie D C, Jessberger S, Consiglio A, San 
Emeterio J, Hortigüela R, Marqués-Torrejón M Á, Nakashima K, Colak D, Götz M, Fariñas I, Gage F H (2010). Signaling through BMPR-IA regulates quiescence and long-term activity of neural stem cells in the adult hippocampus. Cell Stem Cell, 7(1): 78-89

Morton G J, Cummings D E, Baskin D G, Barsh G S, Schwartz M W (2006). Central nervous system control of food intake and body weight. Nature, 443(7109): 289-295

Najmabadi H, Hu H, Garshasbi M, Zemojtel T, Abedini S S, Chen W, Hosseini M, Behjati F, Haas S, Jamali P, Zecha A, Mohseni M, Püttmann L, Vahid L N, Jensen C, Moheb L A, Bienek M, Larti F, Mueller I, Weissmann R, Darvish H, Wrogemann K, Hadavi V, Lipkowitz B, Esmaeeli-Nieh S, Wieczorek D, Kariminejad R, Firouzabadi S G, Cohen M, Fattahi Z, Rost I, Mojahedi F, Hertzberg C, Dehghan A, Rajab A, Banavandi M J, Hoffer J, Falah M, Musante L, Kalscheuer V, Ullmann R, Kuss A W, Tzschach A, Kahrizi K, Ropers H H (2011). Deep sequencing reveals 50 novel genes for recessive cognitive disorders. Nature, 478(7367): 57-63

Nakada D, Saunders T L, Morrison S J (2010). Lkb1 regulates cell cycle and energy metabolism in haematopoietic stem cells. Nature, 468 (7324): 653-658

Orford K W, Scadden D T (2008). Deconstructing stem cell selfrenewal: genetic insights into cell-cycle regulation. Nat Rev Genet, 9 (2): $115-128$

Paik J H, Ding Z, Narurkar R, Ramkissoon S, Muller F, Kamoun W S, Chae S S, Zheng H, Ying H, Mahoney J, Hiller D, Jiang S, Protopopov A, Wong W H, Chin L, Ligon K L, DePinho R A (2009). FoxOs cooperatively regulate diverse pathways governing neural stem cell homeostasis. Cell Stem Cell, 5(5): 540-553

Park H R, Park M, Choi J, Park K Y, Chung H Y, Lee J (2010). Neuroscience Letters. Neurosci Lett, 482: 235-239

Renault V M, Rafalski V A, Morgan A A, Salih D A M, Brett J O, Webb A E, Villeda S A, Thekkat P U, Guillerey C, Denko N C, Palmer T D, Butte A J, Brunet A (2009). FoxO3 regulates neural stem cell homeostasis. Cell Stem Cell, 5(5): 527-539

Schulz T J, Huang P, Huang T L, Xue R, McDougall L E, Townsend K L, Cypess A M, Mishina Y, Gussoni E, Tseng Y H (2013). Brown-fat paucity due to impaired BMP signalling induces compensatory browning of white fat. Nature, 495(7441): 379-383

Schulz T J, Tseng Y H (2009). Emerging role of bone morphogenetic proteins in adipogenesis and energy metabolism. Cytokine Growth Factor Rev, 20(5-6): 523-531

Sims J K, Manteiga S, Lee K (2013). Towards high resolution analysis of metabolic flux in cells and tissues. Curr Opin Biotechnol, 24(5): 933939

Song J, Zhong C, Bonaguidi M A, Sun G J, Hsu D, Gu Y, Meletis K, Huang Z J, Ge S, Enikolopov G, Deisseroth K, Luscher B, Christian K M, Ming G L, Song H (2012). Neuronal circuitry mechanism regulating adult quiescent neural stem-cell fate decision. Nature, 489 (7414): 150-154

Spalding K L, Bergmann O, Alkass K, Bernard S, Salehpour M, Huttner H B, Boström E, Westerlund I, Vial C, Buchholz B A, Possnert G, Mash D C, Druid H, Frisén J (2013). Dynamics of hippocampal neurogenesis in adult humans. Cell, 153(6): 1219-1227

Steib K, Schäffner I, Jagasia R, Ebert B, Lie D C (2014). Mitochondria modify exercise-induced development of stem cell-derived neurons in the adult brain. J Neurosci, 34(19): 6624-6633

Stein L R, Imai S (2014). Specific ablation of Nampt in adult neural stem cells recapitulates their functional defects during aging. EMBO J, 33 (12): 1321-1340

Stoll E A, Cheung W, Mikheev A M, Sweet I R, Bielas J H, Zhang J, Rostomily R C, Horner P J (2011). Aging neural progenitor cells have decreased mitochondrial content and lower oxidative metabolism. J Biol Chem, 286(44): 38592-38601

Suda T, Takubo K, Semenza G L (2011). Metabolic regulation of hematopoietic stem cells in the hypoxic niche. Cell Stem Cell, 9(4): 298-310

Suh H, Deng W, Gage F H (2009). Signaling in adult neurogenesis. Annu Rev Cell Dev Biol, 25(1): 253-275

Teperino R, Amann S, Bayer M, McGee S L, Loipetzberger A, Connor T, Jaeger C, Kammerer B, Winter L, Wiche G, Dalgaard K, Selvaraj M, Gaster M, Lee-Young R S, Febbraio M A, Knauf C, Cani P D, Aberger F, Penninger J M, Pospisilik J A, Esterbauer H (2012). Hedgehog partial agonism drives Warburg-like metabolism in muscle and brown fat. Cell, 151(2): 414-426

Teperino R, Schoonjans K, Auwerx J (2010). Perspective. Cell Metab, 12: $321-327$

Vander Heiden M G, Cantley L C, Thompson C B (2009). Understanding the Warburg effect: the metabolic requirements of cell proliferation. Science, 324(5930): 1029-1033

Varum S, Rodrigues A S, Moura M B, Momcilovic O, Easley C A 4th, Ramalho-Santos J, Van Houten B, Schatten G (2011). Energy metabolism in human pluripotent stem cells and their differentiated counterparts. PLoS ONE, 6(6): e20914

Villeda S A, Luo J, Mosher K I, Zou B, Britschgi M, Bieri G, Stan T M, Fainberg N, Ding Z, Eggel A, Lucin K M, Czirr E, Park J S, Couillard-Després S, Aigner L, Li G, Peskind E R, Kaye J A, Quinn J F, Galasko D R, Xie X S, Rando T A, Wyss-Coray T (2011). The ageing systemic milieu negatively regulates neurogenesis and cognitive function. Nature, 477(7362): 90-94

Zhang J, Nuebel E, Daley G Q, Koehler C M, Teitell M A (2012). Metabolic regulation in pluripotent stem cells during reprogramming and self-renewal. Cell Stem Cell, 11(5): 589-595

Zhao C, Deng W, Gage F H (2008). Mechanisms and functional implications of adult neurogenesis. Cell, 132(4): 645-660 